\title{
Khon Lakhon Performances at Dance Colleges in Central Thailand
}

\author{
Somchai Fonramdee ${ }^{1}$, Songkoon Chantachon ${ }^{1} \&$ Marisa Koseyayothin ${ }^{2}$ \\ ${ }^{1}$ The Faculty of Cultural Science, Mahasarakham University, Khamriang Sub-District, Maha Sarakham, Thailand \\ ${ }^{2}$ Kanchanapisek Non-Formal Education Centre (Royal Academy), Salaya Sub-District, Nakhon Pathom, \\ Thailand \\ Correspondence: Somchai Fonramdee, The Faculty of Cultural Science, Mahasarakham University, Khamriang \\ Sub-District, Kantarawichai District, MahaSarakham Province 44150, Thailand. E-mail:sfonramdee145 \\ (a)hotmail.com
}

Received: April 22, 2014 Accepted: May 20, 2014 Online Published: June 4, 2014

doi:10.5539/ach.v6n2p77 URL: http://dx.doi.org/10.5539/ach.v6n2p77

\begin{abstract}
This is a qualitative investigation that aims to analyze the current state and problems of Khon Lakhon performances in educational institutions of Central Thailand. The investigation was conducted from 1 May 2011 to 30 September 2012. 150 individuals were purposively selected as respondents for the research from five purposively selected institutions. The results show that Khon performances have been inherited by general society and incorporated into the education system at specialist dance schools and colleges. The performers have inherited their dance technique and understanding from teachers at a variety of institutes nationwide and honed their skills under the supervision of qualified instructors.Khon productions must be performed by skilled students, who have been trained according to a set curriculum. There are some problems with the Khon performances because the numbers of suitable candidates for each role in each age group are not equal and performers with a mixture of different age and skill levels must be used to complete the cast. The costumes, music, staging and props used by the five sample groups are very similar because they follow the traditional khon customs of the royal courts. The performance costumes and props used by educational institutions are not complete sets and cause the production quality to suffer. There are two clear areas of Khon Lakhon production in educational institutions that require development: the performers and the components.
\end{abstract}

Keywords: Khon Lakhon, performing arts, Thailand, education, drama

\section{Introduction}

Thailand has its own cultural heritage, which has an important social and economic function. Thai culture is so well preserved and recognized due in a large part to the dedication of the monarchy. His Majesty King Bhumibol Adulyadej said 'the academic works of education, art and culture are representations of creative, intellectual and spiritual growth and are both the cause and result of prosperity. These factors will help us preserve and maintain our country for years to come' (Office of the National Culture Commission, 2002). Art and culture in any country cause close relationships between people, regardless of ethnicity and background. In most societies, people follow traditions that have been inherited from one generation to the next. These often reflect lifestyle, beliefs, literature, language and law. It is important that communities and societies maintain their cultures through learning processes and institutional education. In these circumstances, students can formally understand the components of their culture and societies, enabling them to think, imagine, analyze the problems and discover solutions (Chongdarakul, 2010).

There is a variety of performing arts in Thailand, from village to royal level, which transmit knowledge far beyond their original boundaries and are transmitted throughout the world. The Thai performing arts are believed to have derived from one of two phenomena: emotional trauma and religion or faith. Accordingly, people either developed their manners and emotional behavior in the art forms or paid homage to respected spirits. The Thai dramatic art performances were and still are performed at royal, state and civil ceremonies. While each has specific features, all are created as cultural heritage for future generations (Fine Arts Department, 2008).

Khon is a dramatic performance that has been produced in Thailand since the twentieth Buddhist century (Yupoti, 1968). In the Ayutthaya Kingdom, a discourse known as Punnowart by Maha Naga of Wat Tha Sai narrated the celebration of Phra Phuttabat with a shadow play (Yupoti, 1973). The puppets were made from animal skin and 
the principal characters were the hero, the heroine, the ogre and the monkey. Over time, audiences and puppeteers came to act and dance on behalf of the puppets with costumes as face masks. Originally the Khon performers covered their faces with masks and did not speak, with voiceovers providing the narrative (Yupoti, 1951). Later performers removed their masks. The most popular tale is the Ramayana epic (Tawatachakunchorn, 2002).

As with other Thai performing arts, Khon Lakhon is confronted by problems that have been caused by worldwide economic and social changes. Given the importance of Thai cultural heritage and the significance given to performing arts and education by the King, the research team was interested in assessing the state of khon lakhon productions in educational institutions and the problems it faces.

\section{Methodology}

This is a qualitative investigation using documentary research and field study methods. The aims of the investigation were to analyze the current state and problems of KhonLakhon performances in educational institutions of Central Thailand. The investigation was conducted from 1 May 2011 to 30 September 2012. 150 individuals were purposively selected as respondents for the research from five purposively selected institutions (Table 1).

Table 1. A list of institutions selected for the study

\begin{tabular}{|c|c|c|c|}
\hline & Province & Name & Address \\
\hline 1 & Bangkok & Bunditpatanasilpa Institute & Ratchinee Road, PhraNakhon District, Bangkok, 10200 \\
\hline 2 & NakhonPathom & The Dramatic Arts College & $\begin{array}{l}\text { Salaya Sub-district, Mueang District, NakhonPathom, } \\
73170\end{array}$ \\
\hline 3 & Lopburi & Lopburi Dramatic Arts College & Ramdecho Road, Mueang District, Lopburi, 15000 \\
\hline 4 & Suphanburi & $\begin{array}{l}\text { Suphanburi Dramatic Arts } \\
\text { College }\end{array}$ & $\begin{array}{l}\text { Suphanburi-Chainat Road, Mueang District, } \\
\text { Suphanburi, } 72000\end{array}$ \\
\hline 5 & Ang Thong & $\begin{array}{l}\text { Ang Thong Dramatic Arts } \\
\text { College }\end{array}$ & $\begin{array}{l}\text { Pang Kaew Sub-district, Mueang District, Ang Thong, } \\
14000\end{array}$ \\
\hline
\end{tabular}

Field data was collected by means of basic survey, observation, interview and focus group discussion. Basic survey was used to collect general information about the institutions and the respondents. Observation was split into two types: participant and non-participant. For non-participant observation, the research team monitored performance preparation, rehearsals, management and production from an audience perspective. For participant observation, the research team was actively involved in each stage of performance. Three types of interview were used during data collection, informal interviews were held intermittently with respondents in each of the five study locations and non-limited in question or scope. Formal interviews were held with specifically arranged locations, times and questions. The formal interviews were divided into three sections: background of khon lakhon performance at educational institutions in Central Thailand, current state of khon lakhon performance at educational institutions in Central Thailand and problems with khon lakhon performance at educational institutions in Central Thailand. Focus group discussions were arranged at each location with seven or eight individuals to clarify any outstanding issues and conclude the data collection. Collected data was organized according to the research aims and validated using the methodological triangulation process of Denzin (1970; Chantavanich, 2004). Data was analyzed by analytic induction and typological analysis. The results are here presented as a descriptive analysis.

\section{Results}

Although Khon performances originated in the royal courts, they have been inherited by general society and incorporated into the education system at specialist dance schools and colleges. Dramatic arts education is supported by the government as an expression of Thai cultural heritage that helps to conserve and adapt traditional customs for future generations. The government institutions of the central region that support dramatic arts education are Bunditpatanasilpa Institute, The Dramatic Arts College, Lopburi Dramatic Arts College, Suphanburi Dramatic Arts College and Ang Thong Dramatic Arts College. These institutions teach four types of Khon performance: khon klang blaeng, khon na jaw, khon chak and khon na fai. Khon klang blaeng is staged outdoors with no man-made set. The performers must all wear character masks. Khon na jaw is performed 
in front of a large canvas. Khon chak is performed with a background and man-made set. Khon na fai is a short midday performance. Stage performances are organized for local society with the casts formed by teachers and students.

Performers in Bunditpatanasilpa Institute Khon productions are undergraduate students from the College of Music in the Faculty of Arts with a background in secondary level performing arts. The performers have inherited their dance technique and understanding from teachers at a variety of institutes nationwide and honed their skills in the Bunditpatanasilpa Institute, under the supervision of qualified instructors. Given the large field of candidates from which to select performers, the Bunditpatanasilpa Institute is able to name leads and understudies for every show. 'There are very few problems with casting. It is very rare for teachers to be required to fill roles' (Ruetithep Taohiran, personal communication, 2012). The Dramatic Arts College, Suphanburi Dramatic Arts College and Ang Thong Dramatic Arts College all open casting to secondary and undergraduate level students. Performers could be any age from eleven years old upwards. 'There are many prospective performers, so there are hardly any casting difficulties' (Pusit Rungkaew, personal communication, 2012). Lopburi Dramatic Arts College performances are also open to secondary and undergraduate level students but there are very few members of the Khon department. For this reason, they occasionally need help from students of other colleges. 'Sometimes teachers are required to make up the numbers' (Sayan Chaloeyreuk, personal communication, 2012). The situation in Lopburi shows that Khon productions must be performed by skilled students, who have been trained according to a set curriculum. Specifically, those actors wishing to play the role of the hero must have studied how to do so. The same can be said of the heroine, the ogre and the monkey. Each of the lead actors or actresses must also know how to complete the Wai Kru ceremony, which must be observed before each show. The four colleges each teach more secondary level students than undergraduate students. This causes some problems with the Khon performances because the numbers of suitable candidates for each role in each age group are not equal and performers with a mixture of different age and skill levels must be used to complete the cast and understudies.

Khon performances are split into different acts but for this investigation the research team only studied two: Ton Nang Loy and Ton Maiyarap Sakot Tap. There were two reasons for choosing these two acts. They both reveal Thai artistic culture and, importantly, they both include performances by each of the four character types. The dance postures for the characters all differ but they follow the same musical rhythm, set by the band, creating a 'unity of diversities'. At Bunditpatanasilpa Institute Ton Nang Loy is the most common production because the duration is suitable. The act is usually performed as a khon na fai. The Institute has never held a full Ton Maiyarap Sakot Tap performance because it is too long, 'but occasionally twenty minute excerpts will be adapted' (Ruetithep Taohiran, personal communication, 2012). The Dramatic Arts College has a number of expert producers on their teaching staff, who are able to create performances depending on time and occasion. For the most part, performances fall into one of two categories: one hour long and over one hour long. Occasionally, the Ton Maiyarap Sakot Tap is played in a full three-hour production using either khon klang blaeng or khon na jaw style. 'Sometimes short twenty to thirty minute segments of the Ton Maiyarap Sakot Tap are performed as khon na fai' (Teerapat Tongnim, personal communication, 2012). Lopburi Dramatic Arts College gives one-hour adaptations of Ton Nang Loy in khon klang blaeng or khon na jaw style. Ton Maiyarap Sakot Tap is shown as a four-hour khon klang blaeng or khon na jaw production, although 'since 1983 it has been adapted as a three-hour show on three or four occasions' (Wanlop Tongsuwan, personal communication, 2012). There are also short matinee excerpts. Suphanburi Dramatic Arts College holds one-hour khon klang blaeng or khon na jaw performances of Ton Nang Loy but do not perform Ton Maiyarap Sakot Tap because it is too big. Ang Thong Dramatic Arts College holds adapted productions and occasionally joins them to form a larger show. In each institution, a variety of different adaptations and types of production are held. This is made possible by the skill of the teachers who write the scripts and create the production design, all the while following the guidelines of the Department of Fine Arts.

The costumes, music, staging and props used by the five sample groups are very similar because they follow the traditional khon customs of the royal courts. The primary heroes, heroines, ogres and monkeys wear individually specific patterned, embroidered and brocaded costumes, while the ensemble cast members wear generic sequined pieces. At Bunditpatanasilpa Institute, there are enough costume pieces for a full set but this is only if the costumes for leading performers and ensemble cast are mixed. 'Consequently, the performance costumes are not complete sets and do not always look correct' (Ruetithep Taohiran, personal communication, 2012). If extra pieces are needed, the Institute must borrow or seek sponsorship because their budget is insufficient to buy new items. This situation is the same for The Dramatic Arts College, Lopburi Dramatic Arts College, Suphanburi Dramatic Arts College and Ang Thong Dramatic Arts College. The main props needed are a large bed, a small 
bed and traditional triangular pillows. 'The Dramatic Arts College must sometimes borrow props because it doesn't have a complete set or the budget to buy new props' (Pradit Silpasombat, personal communication, 2012). Lopburi Dramatic Arts College and Suphanburi Dramatic Arts College must also borrow props and their staging set is incomplete. Ang Thong Dramatic Arts College is in the same situation regarding props but, rather than borrowing additional items, they simply cut the props from the script. 'This negatively affects the overall performance (Kittipong Jansamut, personal communication, 2012). Each institution employs their own pipat ensemble to play the score for the khon production. Either a two-flute or full pipat ensemble is used for the music, depending on the suitability for the location and occasion.

'If khon performances do not have complete components or are different from one institution to the next, the audience becomes confused' (Chaowanat Pengsuk, personal communication, 2012). This is a consequence of incomplete costumes or props, inadequately trained performers and adaptations to the traditional scripts. While casting is only a problem at Lopburi Dramatic Arts College, khon performer pools in every institution will soon be affected by the 'low enrolment rate of students wishing to study khon lakhon' (Chaowanat Pengsuk, personal communication, 2012). This is a sign that young members of modern society do not appreciate khon performance and also explains why college budgets are insufficient to buy required props and costumes.

\section{Discussion}

There are two clear areas of Khon Lakhon production in educational institutions that require development: the performers and the components. Khon performers need good teachers from whom they can learn and obtain skills and related knowledge. This is consistent with the findings of Chommanak Sopon (1998). Sopon identified three development period s of Khon Lakhon. These were the traditional period, the period of school education and the period of revitalization from royal courts to higher educational institutions under government supervision. Khon teachers should focus on the production of dramatic artists and their creativity. Teachers must instruct their students how to perform the Wai Kru ceremony, perform in each role and respect the character they are playing. Each performer must know the techniques and styles of other roles. Main characters should be played by senior students, while junior students should be restricted to chorus parts because their experience levels are insufficient for the main roles. Costumes must be specifically made for each character, music must be suitable for the venue and complete prop sets must be used for all performances. Costume managers and stage designers must know the history, standards, traditions and aesthetics of Khon performance (Wongpaiboon, 2010).

The influx of foreign culture in Thai society has had a strong influence on socio-economic changes, tangible and intangible (Wise, 1956). The problems facing Khon Lakhon productions in educational institutions are the inconsistency of the performances and the content being taught and learned in schools. These inconsistencies come from a lack of people enrolling on Khon Lakhon courses and choosing to study traditional Thai dance. Unqualified and untrained performers are thus required to make up show numbers. These problems were consistent with the findings of Savit Phongvatch (2005), who found that performers playing the role of the ogre needed thorough training from a qualified instructor. However, for complete training, a large budget is required and the lack of students causes significant financial shortages.

Although the stories of the Thai Khon productions are similar and are all based on the Ramayana, each individual performance requires specific management and planning (Srinil, 2010). Strategy, planning, execution and cooperation are all vital for Thai Khon Lakhon performances (Kasemsin, 1983). The model of performing arts at each of the five educational institutions studied during this investigation had been inherited from previous generations. Changes and adaptations had been made so that fast and convenient performances could be produced. These are responses to the faster pace of human society and consistent with the findings of Ngampit Satsanguan (2009) and Songkoon Chantachon (2000), who found that the primary function of culture is to meet basic human needs. Khon performances have been adapted to satisfy the audience's interest using a cultural administrative process. Khon Lakhon productions have thus been able to maintain national culture and heritage.

\section{Conclusion}

Dance colleges in Central Thailand have the responsibility of continuing the fine traditions of Thai classical dance. Khon Lakhon is just one form of dance that the colleges teach and develop. It is necessary for Khon productions to be performed by skilled students with advanced training. The numbers of suitable candidates for Khon Lakhon roles have suffered from social changes and this weakens the overall level of performances at Central Thai dance colleges. The quality and availability of costumes, music, staging and props at dance colleges in Central Thailand are all significantly affected by budget. From the circumstances and problems identified by this investigation, there are two clear areas of Khon Lakhon production in educational institutions that require development and research: the performers and the components. Further research will be crucial to the 
continuation of Khon Lakhon traditions at dance colleges in Central Thailand.

\section{References}

Chantachon, S. (2000). Advanced cultural research [in Thai]. MahaSarakham: Mahasarakham University.

Chantavanich, S. (2004). Data analysis in qualitative research [in Thai]. Bangkok: Chulalongkorn University Press.

Chongdarakul, S. (2010). Traditional games of local communities in the Mae Klong River: Management for local cultural transformation of basic education schools [in Thai]. PhD thesis. Mahasarakham University, MahaSarakham.

Denzin, N. K. (1970). The research act in sociology. Chicago: Aldine.

Fine Arts Department. (2008). Registration information: Variety shows series dancing [in Thai]. Bangkok: Ammarin Printing and Publishing.

Kasemsin, S. (1983). Administration [in Thai]. Bangkok: Thai WattanaPanit.

Office of the National Culture Commission. (2002). The artists of the literary field [in Thai]. Bangkok: Teachers' Printing at LatPhrao.

Phongvatch, S. (2005). Creating a giant Khon artist [in Thai]. PhD thesis, Chulalongkorn University, Bangkok.

Satsanguan, N. (2009). Qualitative research in anthropology [in Thai]. Bangkok: Chulalongkorn University.

Sopon, C. (1998). Development study of Thai dramatic arts performance in Thailand [in Thai]. $\mathrm{PhD}$ thesis. Chulalongkorn University, Bangkok.

Srinil, S. (2010). A comparative study of Kha Thogli of India and Thai of Thailand [in Thai]. Phuket: Prince of Songkhla University.

Tawatachakunchorn, N. (2002). Classical dance at entertainment venues. $\mathrm{PhD}$ thesis. Chulalongkorn University, Bangkok.

Wiese, D von (1956). The sociological study of change: Transaction of the third world congress of sociology. Amsterdam: International Sociological Association.

Wongpaiboon, P. (2010). Application of contemporary performing arts in Central Thailand [in Thai]. PhD thesis. Mahasarakham University, Maha Sarakham.

Yupoti, T. (1951). An explanation of Thai classical dance. Bangkok: Phra Jan Press.

Yupoti, T. (1968). Khon. Bangkok: Fine Arts Department.

Yupoti, T. (1973). Dance drama or a manual of Thai classical dance. Bangkok: Fine Arts Department.

\section{Copyrights}

Copyright for this article is retained by the author(s), with first publication rights granted to the journal.

This is an open-access article distributed under the terms and conditions of the Creative Commons Attribution license (http://creativecommons.org/licenses/by/3.0/). 